\title{
A MERCANTILIZAÇÃo DA CULTURA NA NARRAÇÃO DE RODRIGO S.M., EM A HORA DA ESTRELA, DE CLARICE LISPECTOR
}

\author{
Bárbara Del Rio Araújo*
}

RESUMO: Este artigo pretende entender como a configuração narrativa desempenhada pelo narrador-personagem Rodrigo S.M. formaliza o atuante paradigma da indústria cultural na composição estética e também a problemática da identidade nacional ao seguir as novas tendências sobre o uso da linguagem. A premissa da pesquisa se relaciona às dificuldades colocadas no momento da narração, as quais suscitam, para além da discussão da escrita de si e da alteridade, "o sentimento acabrunhador da posição em falso de tudo o que concerne à cultura brasileira”. (ARANTES, 1997, p.14). O romance $A$ bora da estrela, em função do engenho narrativo, se faz importante no questionamento dos limites da representação artística e no estatuto ambíguo da condição brasileira, a revelar que "a vida no capitalismo tardio é um contínuo rito de iniciação. Todos têm de mostrar que se identificam integralmente com o poder de quem não cessam de receber pancadas" (ADORNO, 2006, p.127). Em função dos personagens, Rodrigo e Macabéa, o romance de Clarice Lispector aproxima o trabalho do escritor ao da datilografa, contribuindo para evidenciar o esvaziamento ideológico da sociedade industrial e a inserção da cultura na lógica do fetichismo e da mercantilização. Assim, essa análise refletirá sobre como o narrador, apesar da sua racionalização, está atrofiado na capacidade de narrar, reproduzindo a implacável ideologia das massas.

PALAVRAS-CHAVE: $A$ hora da estrela; Indústria cultural; Narrador.

A obra A hora da estrela foi publicada em 1977 por Clarice Lispector, sendo fortemente aclamada pela fortuna crítica, que logo reconheceu uma nova perspectiva de trabalho com a linguagem e com a sondagem psicológica. Nesse sentido, enaltecia-se a capacidade da narrativa em superar a referenciação externa, isto é, o "abandono da figuração absoluta do real" (GOTLIB, 1995, p.411). A questão colocada pelos estudiosos girava em torno do processo agônico da escrita de si e das relações de alteridade na representação do escritor e dos personagens. Benedito Nunes, em $O$ drama da linguagem, ainda que preocupado com a ação ficcional no jogo das identidades, enuncia elementos importantes, os quais fazem a realidade ainda mais presente na configuração do texto. Em referência ao enredo, o crítico afirma:

\footnotetext{
A voz do narrador-personagem é bastante jocosa para anunciar que a história pobre da datilógrafa desenrolar-se-á acompanhada pelo ruflar de um tambor "sob o patrocínio do refrigerante mais popular do mundo, com gosto do cheiro de esmalte de unhas e de sabão Aristolino" e bastante séria para mediar o confronto da situação humana de Macabéa com o ofício e o papel de escritor. As peripécias da narração envolvem o dificultoso e problemático do ato de escrever - questionando quanto ao seu objeto, à sua finalidade e aos seus procedimentos. (NUNES, 1989, p.163)
}

O estudioso chama atenção para a diferença estilística na narração do personagem Rodrigo S.M. Nisso, ele enuncia como essa se influencia pelo patrocínio de produtos

\footnotetext{
* Doutora em Estudos Literários pela Universidade Federal de Minas Gerais (UFMG). Professora efetiva do Centro Federal de Educação Tecnológica de Minas Gerais (CEFET-MG).
} 
industriais ao passo que tenta ser humano e solidário com o drama de Macabéa. Perceba que os fatores sociais e a representação do real não são abandonados. Eles são partes da reflexão frequente sobre o modo de narrar. Rodrigo S.M. é um escritor medíocre que busca ascensão econômica e status social. Entretanto, foge ao trabalho duro e afirma preferir meditar a escrever: "Eu medito sem palavras e sobre o nada. O que me atrapalha a vida é escrever." Ele, assim, reconhece que o mercado é o que se almeja dessa narração: "é uma histórica tecnicolor para ter algum luxo, por Deus, que eu também preciso" (LISPECTOR, 1995, p.23).

Nesse aspecto, percebe-se que, além da história a ser contada, existe uma outra que diz respeito ao complexo modus vivendi de um escritor moderno brasileiro que precisa do ofício para sustento e que sofre com as tendências, desempenhando em consequência uma escrita reflexiva, não somente de si, mas sobretudo da sociedade de consumo. Além da crise do indivíduo, $A$ bora da estrela representa a fetichização em assumir padrões como se fossem parte do autoconhecimento:

Proponho-me a que não seja complexo o que escreverei, embora obrigado a usar as palavras que vos sustentem. A história - determino com falso livre arbítrio vai ter uns sete personagens e eu sou um dos mais importantes deles, é claro. Eu, Rodrigo S.M. Relato antigo, este, pois não quero ser modernoso e inventar modismo à guisa de originalidade. Assim é que experimentarei contra os meus hábitos uma história com começo, meio e "gran finale" seguindo de silêncio e de chuva caindo. (LISPECTOR, 1995, p.27)

Rodrigo diz querer escapar ao modismo, se escondendo atrás de uma tradição segura e com um final espetacular no desempenho narrativo. Ainda que se esquive de uma moda, ele recorre a outra (a da tradição), repetindo chavões de teoria literária. Assim, no trecho seguinte, Rodrigo reflete sobre a necessidade de o estilo se adequar ao objeto: "Pretendo, como já insinuei, escrever de modo cada vez mais simples. Aliás, o material de que disponho é parco e singelo demais" (LISPECTOR, 1995, p.28). O narrador está introduzindo Macabéa, uma simples datilografa que veio do sertão alagoano para o Rio de Janeiro. Tentando ter domínio do jogo narrativo, ele afirma contrariar tendências e escrever o que quer: "O que eu narrarei será meloso? Tem tendência mas então agora mesmo seco e endureço tudo. E pelo menos o que eu escrevo não pede favor a ninguém e não implora socorro" (LISPECTOR, 1995, p.31). Entretanto, a autenticidade que tanto busca acaba escapando. A narrativa não segue linearmente, isto é, começo, meio e gran finale, a simplicidade almejada para com Macabéa, torna-se dificultosa e, por fim, percebemos um narrador consternado à valores que embora diga não seguir, está completamente imerso neles: "Limito-me a humildemente mas sem fazer estardalhaço de minha humildade que já não seria humildade - limito-me a contar as fracas aventuras de uma moça em uma cidade toda feita contra ela" (LISPECTOR, 
1995, p.29). Esse rígido controle que busca no desempenho narrativo, mostra que "a força social contemporânea o força a decidir a favor de que causa colocará sua atividade. Vós lhes demonstrais que, sem o admitir, ele trabalha a serviço de certos interesses de classe" (BENJAMIN, 1994, p.120).

O narrador cria Macabéa a partir de suas observações em um ônibus da cidade, sente por ela compadecimento e, apesar de sentir atraído pela realidade que o cerca, se coloca distanciado do objeto e reconhece que falar sobre ela é "tirar ouro do carvão". Afirma ainda muito se diferenciar da pobre coitada, já que "para falar da moça tenho que não fazer a barba durante dias e adquirir olheiras escuras por dormi pouco, só cochilar de pura exaustão, sou um trabalhador manual. Além de vestir-me com roupa velha rasgada. Tudo isso para me pôr no nível da nordestina” (LISPECTOR, 1995, p.34). Nisso, Rodrigo S.M. apela para condição de classe para marcar o seu distanciamento: "sou um homem que tem mais dinheiro do que os que passam fome". A reflexão sobre a escrita o aproxima e o afasta de Macabéa quando diz: "Que mais? Sim, não tenho classe social, marginalizado que sou. A classe alta me tem como um monstro esquisito, a média com desconfiança de que eu possa desequilibrá-la, a classe baixa nunca vem a mim" (LISPECTOR, 1995, p.33).

A problemática que se coloca na escrita demonstra a busca por autenticidade do escritor e as condições sociais que o diferenciem da personagem conterrânea. Ele tenta marcar essa diferença inclusive em relação ao leitor, mostrando que a condição social determina quem o lê:

\footnotetext{
Se o leitor possui alguma riqueza e vida bem acomodada, sairá de si para ver como é às vezes o outro. Se é pobre não estará me lendo porque ler-me é supérfluo para quem tem uma leve fome permanente. Faço aqui o papel de vossa válvula de escape e da vida massacrante da média burguesia. (LISPECTOR, 1995, p.46)
}

Perceba que, ainda que exista crítica em relação a sua condição de burguês médio, ele a utiliza para se diferenciar dos outros. A personagem Macabéa é sempre o seu para comparações e Rodrigo se gaba por conseguir se exprimir e escrever, enquanto ela se silencia, vive no acaso. Interessante é perceber que, ao dizer da pobreza social e mental da personagem, ele esboça a si e toda a crise de representação em uma sociedade industrial. Rodrigo narra Macabéa como uma datilografa simples, influenciável dando a entender muitas diferenças entre eles. Contudo, são eles muito próximos. Para além de um jogo de máscaras, criador e criatura, ambos padecem da mercantilização cultural, e a consciência do narrador não o neutraliza do problema. Ele é invadido pelas tendências, causando sempre tons reflexivos à narração. O trecho a seguir revela a criticidade e os juízos perante o gosto de Macabea, 
entretanto, ao estilizá-la, acaba incorrendo no mesmo processo produtivo, mostrando assim a sua reprodução perpétua:

Todas as madrugadas ligava o rádio emprestado por uma colega de moradia, Maria da Penha, ligava bem baixinho para não acordar as outras, ligava invariavelmente para a Rádio Relógio, que dava "hora certa e cultura”, e nenhuma música (...) Foi assim que aprendeu que o Imperador Carlos Magno era na terra dele chamado de Carlous. Verdade que nunca achara modo de aplicar essa informação. (...) Outra vez ouvira: Arrepende-te em Cristo e Ele te dará felicidade" Então ela se arrependera. Como não sabia de que, arrependia-se toda e de tudo. O pastor também falava que a vingança é coisa infernal. Então ela não se vingava. (LISPECTOR, 1995, p.53)

Rodrigo descreve Macabéa como uma colecionadora de anúncios, entusiasta com as novidades que traziam. Além disso, sonhava em ser artista de cinema como Marylin Monroe ou Greta Garbo. Narra que, uma vez, se interessou pelo livro Humilhados e ofendidos pela capa, que estava na mesa do patrão Raimundo, que a constrangia. Entretanto, por julgar que nunca fora humilhada ou ofendida, não procurou lê-lo. Assim, o narrador questiona a fibra da nordestina e nisso impõe à narrativa o ritmo crítico. Mas se trata de uma ilusão. Ele também segue os ditames da cultura industrial na narrativa, o que mostra o quanto dela é impossível escapar. O parâmetro utilizado para o título do livro que está produzindo assim como para a personagem é o clichê cinematográfico: "pois na hora da morte a pessoa se torna brilhante estrela de cinema, é o instante de glória de cada um e é quando como no canto coral se ouvem agudos sibilantes" (LISPECTOR, 1995, p.44).

Ainda que não receba nenhum suporte das indústrias, dos anúncios de produtos, isso se destaca como elemento ideológico, mantendo a narrativa nas tendências mercadológicas. Aderida à mercadoria cultual, a narração de Rodrigo S.M., ainda que busque criticidade tem caráter fetichista já que "diz respeito à ocultação do caráter de valor-trabalho que ela possui por meio da idolatria do seu aspecto de coisa" (DUARTE, 2003, p.32):

Também esqueci de dizer que o registro que em breve vai ter que começar - pois já não aguento a pressão dos fatos - o registro que em breve vai ter que começar é escrito sob o patrocínio do refrigerante mais popular do mundo que nem por isso me paga nada, refrigerante esse espalhado por todos os países (...) Ele é um meio da pessoa atualiza-se e pisar na hora presente. (LISPECTOR, 1995, p.38)

O aspecto fetichizado da narrativa e do seu narrador Rodrigo S.M. muito se assemelha ao comportamento de Macabéa. Ainda que Rodrigo queira dela se apartar, sendo enfático que a moça "nem se dava conta de que vivia numa sociedade técnica onde ela era um parafuso dispensável" (LISPECTOR, 1995, p.44), ele atua no mesmo papel, desconhecendo a configuração social que lhes imputa determinado comportamento: "Para ela a realidade era 
demais para ser acreditada. Aliás a palavra realidade não lhe dizia nada. Nem a mim, por Deus” (LISPECTOR, 1995, p.49).

É justamente essa realidade industrial que os acolhe e os aproximam. Adorno explica que, em uma sociedade industrial, o cinema, o rádio, as revistas constituem um sistema. As manifestações estéticas exprimem o mesmo ritmo. Assim, embora os indivíduos se diferenciem, demonstrando a racionalidade, a técnica (esse é o motivo das reflexões de Rodrigo no seu empenho), existe uma tenência fatal à configuração do capital. Ainda que questionador, a subversão do caráter mercantil do produto acaba por reforçar seu valor de troca determinado na sociedade capitalista.

No caso de Macabéa, isso é bastante explorado por Rodrigo, mas é preciso entender que esse juiz padece do mesmo defeito. Ainda que se julgue distanciado economicamente e fisicamente de Macabéa, ele a fomenta e se torna produto dela: "a ação desta história terá como resultado minha transfiguração em outrem e minha materialização em objeto" (LISPECTOR, 1995, p.35). Durante toda a narrativa, Rodrigo se questiona entre seguir a tendência ou ser autêntico o que já nos revela uma atrofia da imaginação e da cultura. Existe um filtro da indústria cultural que, por mais que o renegue, ele está ali:

\begin{abstract}
A capacidade rara de satisfazer minuciosamente as exigências do idioma da naturalidade em todos os setores da indústria cultural torna-se o padrão de competência. O que e como dizem deve ser controlável pela linguagem cotidiana, como no positivismo lógico. Os produtores são especialistas. O idioma exige a mais espantosa força produtiva que ele absorve e desperdiça. Ele superou satanicamente a distinção própria do conservadorismo cultural entre estilo autentico e o estilo artificial. (...) Eis por que o estilo da indústria cultural, que não tem mais de se pôr à prova em nenhum material refratário, é ao mesmo tempo negação do estilo. A reconciliação do universal e do particular, da regra e da pretensão especifica do objeto, que é a única coisa que pode dar substância ao estilo, é vazia, por que não chega mais a haver uma tensão entre os polos: os extremos que se tocam passaram a uma turva identidade, o universal pode substituir o particular e vice versa. (ADORNO; HORKHEIMER, 2006, p.106-107)
\end{abstract}

O narrador de $A$ hora da estrela, em busca de fugir à moda e ter autenticidade, assim se refugia na fantasia romântica retrospectiva de outro estilo. Interessante é que ao fazer isso "nessa pretensão a arte é sempre ao mesmo tempo ideologia" (ADORNO; HORKHEIMER, 2006, p.108) Existe aqui na sua narração um partido, uma tendência à neutralização da cultura embora ele renegue os termos da moda. Impossibilitado de fugir ao jogo S.M. revela que "o denominador cultura já contém o levantamento estatístico, a catalogação, a classificação que introduz a cultura no domínio da administração. Só a subsunção industrializada e consequente é inteiramente adequada a esse conceito de cultura" (ADORNO; HORKHEIMER, 2006, p.108). 
Nesse aspecto, ainda que a fortuna crítica afirme que a obra $A$ bora da estrela se faça ímpar na discussão sobre a crise do sujeito, a busca pelo autoconhecimento, a discussão da identidade e da alteridade, a forma da narrativa nos mostra que a identidade não é possível e se tona balela na sociedade massificada: "na indústria, o indivíduo é ilusório não apenas por causa da padronização do modo de produção. Ele só é tolerado na medida em que sua identidade incondicional com o universal está fora de questão" (ADORNO; HORKHEIMER, 2006, p.108). Contudo, pode-se dizer que ainda que, imersa na cultura de massa, o viés irônico assumido na narrativa, a sua capacidade reflexiva ainda a torna crítica diante da sociedade de consumo. Deste modo, a obra reproduz e critica os rumos da estética diante da sociedade do capital.

Sendo assim, não se trata da escrita de si, em que S.M estabelece relações com o outro, no caso, a outra, Macabéa. Pela configuração da narração, escritor e datilografa se aproximam. Sem individualidade, salvo a diferença social, eles se veem como atores e estão aptos à coisa qualquer, pois o processo de trabalho não os liga a nenhum em particular. São esvaziados e a sua escrita revela a alienação em consequência do fetiche da cultura:

[...] o tipo de experiência que personalizava as palavras ligando-as às pessoas que as pronunciavam foi esvaziado, e a pronta apropriação das palavras faz com que a linguagem assuma aquela frieza que era própria dela apenas nos cartazes e na parte de anúncios dos jornais. (ADORNO; HORKHEIMER, 2006, p.137)

Rodrigo se vê diante de alguns dilemas tais como: seguir as tendências, discutir os padrões literários, o comprometimento diante do objeto representado, permanecer um mau escritor, conseguir luxo com a função empenhada e nisso tudo, ele demonstra além do fetiche da cultura uma questão que diz respeito à condição periférica. Especulando sobre a linguagem, ele afirma:

\footnotetext{
Se em vez de ponto fosse seguido por reticências o título ficaria aberto a possíveis imaginações vossas porventura até malsãs e sem piedade (...) O que eu escrevo é mais do que invenção, é minha obrigação contar sobre essa moça entre milhares delas. E dever meu, nem que seja de pouca arte, o de revela-lhe a vida. Porque há o direito ao grito. (LISPECTOR, 1995, p.27)
}

Rodrigo demonstra domínio e conhecimento sobre os tipos sociais que cercam seu país e quando descreve Olímpico, namorado de Macabéa, afirma que ele era um cabra safado, como se diria no Nordeste, pois não tinha vergonha e exibia um dente de ouro como uma posição na vida. Ao descrever, Glória, carioca da gema, explica que "o fato de ser carioca tornava-a pertencente ao ambicionado clã do sul do país” (LISPECTOR, 1995, p.76). Parafraseando Euclides da Cunha e inspirado em Macabéa, Rodrigo define que "o sertanejo é antes de tudo um paciente" (LISPECTOR, 1995, p.85). Isto posto, pode-se dizer que Rodrigo apresenta na narração a reflexão sobre o país, a identidade cultural nacional em meio à 
influência cultural industrial. Criticamente e de modo ridicularizado, revela que todos os personagens são influenciados pelo cinema e tem apreço pela técnica. Olímpico admira parafusos, é fascinado por touradas; Macabéa acha surpreendente a máquina de escrever e Glória era estenógrafa e pintava os cabelos à moda. Nisso, a narração de Rodrigo revela o quanto afastado estão essas pessoas de uma autenticidade ou de uma modernização. O próprio Rodrigo e seu oficio de escritor nos revela o complexo nacional em meio à indústria cultural. Ele se descreve como um sujeito a cair pra fora do mundo, em que "o pequeno sucesso me invade e me põe no olho da rua" (LISPECTOR, 1995, p.88). Esse desequilíbrio permanente revela "o sentimento acabrunhador da posição em falso de tudo o que concerne à cultura brasileira" (ARANTES, 1997, p.14).

Rodrigo vive às voltas entre pertencer ao público e a si mesmo, como se fosse possível ter autenticidade. Deste modo ele diz: "Sou inocente! Não me consumam! Não sou vendável! Ai de mim, todo na perdição e é como se a grande culpa fosse minha" (LISPECTOR, 1995, p.104). Logo em seguida, ele busca aplausos e conformidade com o padrão cultural: "O final foi bastante grandiloquente para vossa necessidade? Morrendo ela virou ar (LISPECTOR, 1995, p.105). Deste modo, percebemos nele o conflito do escritor brasileiro que se sente às voltas de ora absorver os modelos exógenos, ora negar todos veementemente, exibindo assim as distorções que revelam a penosa construção de uma identidade que varia entre não ser e ser outro, como ilustram Santiago Nunes Ribeiro e Paulo Emílio Sales Gomes.

A vida espiritual nacional, segundo Antonio Candido, sempre se orientou pela dialética do localismo e do cosmopolitismo, manifestada pelos seus modos mais diversos (CANDIDO, 2010, p.117), e nesse aspecto a nossa identidade está na relação entre o que nos é próprio e o que é parte do influxo externo. Isso gerou consequências de pensar (e no penar) do escritor, do intelectual e da própria estética nacional de modo dependente a ilustrar o teorema do desenvolvimento desigual e combinado capitalista. Explico: a nossa formação histórica e cultural se deu de modo dependente, embora autêntico. Nesse sentido, a nossa modernização e construção até os dias atuais se coloca de modo desigual e dependente do influxo externo das grandes potências.

Roberto Schwarz fez um exímio trabalho ao revelar o decoro e a ironia machadiana em relação à combinação escravista e liberal da sociedade novecentista. Nisso, ele mostrou a combinação excêntrica da nossa burguesia em aliar ideias importadas e implantá-las em terra nacional. Em relação ao século XX, em que se insere o romance de Clarice Lispector, o sociólogo analisou, além da obra Verdade Tropical, de Caetano Veloso, o movimento tropicália do qual o músico é parte. Em relação ao movimento, Schwarz afirma que a estetização 
tropicalista revelava a relação entre o antigo que já nos pertencia e sua combinação com o novo, importado:

para os países colonizados e depois subdesenvolvidos, esta configuração é central, pois estes países foram incorporados ao mundo moderno, quero dizer, ao mercado mundial na qualidade de econômica e socialmente atrasados (fornecedores de matéria prima e trabalho barato) de sorte que a ligação destes com o novo se faz através do atraso, que assim se torna estrutural, e em lugar de se extinguir, se reproduz, como atestava a industrialização recente da periferia. (ARANTES, 1992, p.37)

O Brasil, além de ter uma configuração formativa "anfíbia", como diria Silviano Santiago, foi inserido na esteira do moderno, mas seu desenvolvimento nacional não era qualquer, era capitalista, mas um capitalismo específico. Trata-se de um capitalismo tardio e conservador, que mistura o progresso com aspectos coloniais, como discute Chasin ${ }^{1}$. Deste modo, diferentemente do que ocorreria nos países centrais, Glória, Macabéa, Olímpio e o próprio narrador Rodrigo, apesar das suas diferenças de classe, não experimentaram a técnica e a industrialização e se sentem atraídos pelo canto da sereia, sem desfrutar realmente do chamado progresso. Nesse aspecto, em uma economia dependente em tempos da indústria cultural o papel que temos representado é um constante rito de iniciação: "Todos têm de mostrar que se identificam integralmente com o poder de quem não cessam de receber pancadas" (ADORNO, 2006, p.127). Deste modo, as reflexões trazidas por Rodrigo na narração são irônicas, pois ele sabe da impossibilidade da autenticidade de seu ofício no mundo do fetiche. E mais: como se colocar contra esse mercado, sem mesmo experimentá-lo?

A questão nacional diante da indústria cultural e de uma cultura massificada é sempre diluída em prol de uma homogeneização, entretanto nos países periféricos, ainda que a autenticidade se estabeleça mediante a relação com os países centrais, existe nesse cenário uma adesão à uma ordem sem mesmo experienciá-la. Quero dizer, não há uma adoção da ordem e a transformação dela em um programa interno e próprio. Existe a reprodução de um modus que nem ao mínimo é compatível com o desenvolvimento interno. Lembrem-se de que Olímpico, Glória, Macabéa tem fome e não sabem de quê, são apaixonados por uma indústria que nem sequer tiveram acesso: “- Nessa rádio eles dizem essa coisa de cultura e palavras difíceis, por exemplo: o que quer dizer eletrônico?” (LISPECTOR, 1995, p.66)

\footnotetext{
${ }^{1}$ O processo de entificação do capitalismo brasileiro se insere no seu passado histórico e dá a toada via prussiana, como costuma ser a nossa forma de organização. Jose Chasin a denomina como 'via colônia' em que essas relações permanecem e existe a caracterização de um processo tardio de acumulação de capital, consagrando um liberalismo conservador restrito em seu aspecto econômico; a liberdade e a fraternidade se restringira a quem tem dinheiro e se aparelha ao estado. (CHASIN, 1995, p.105).
} 
Dominados por um liberalismo, as especificidades servem à indústria e ao capitalismo, assim, parece simples pensar que a cultura de massa totalizaria as nações colocandoas em mesma condição. O resultado é o encaminhamento para o mesmo fim, entretanto com a diferença que em um capitalismo tardio a coisa se agrava na medida em que a cultura de massa se subordina ao desenvolvimento histórico. As variações históricas revelam homologias entre a cultura, as forças produtivas e as relações sociais. Nesse aspecto, ainda que a indústria cultural paire sob as cabeças e a nação, mais reveladora e incongruente se revela seu papel na periferia, onde a própria industrialização é precária.

Deste modo, é possível novamente uma aproximação entre Macabéa e Rodrigo S.M. Ambos se envolvem com a escrita e precisam de fazer de tudo para se aprumar nesse país atrasado. Macabéa, retirante, sobrevive no Sudeste, desenvolvendo suas habilidades com a máquina de escrever. Diante de uma modernização desigual, ela se desloca e vive indignamente no subúrbio; já Rodrigo escreve em um quarto apertado à exaustão. Ambos são descritos como "apenas um acaso", mas Rodrigo afirma que: "quanto a mim, só me livro de ser apenas um acaso porque escrevo, o que é um ato que é um fato" (LISPECTOR, 1995, p.52).

Rodrigo busca se distanciar da datilógrafa se colocando como escritor, entretanto, durante sua narração, se apega à reprodução das tendências ou de uma tradição sem autenticidade, o que o faz aproximar da simples datilógrafa que está sempre em dúvida e borra demais o papel. Diante de uma manipulação da cultura, esses ofícios se aproximam e a divisão técnica e social do trabalho revelam que tanto o datilógrafo quanto o escritor são meios instrumentais na escrita para os outros, trata-se da reprodução técnica de uma outra ordem, isto é, "direcionado dentro de uma perspectiva de reprodução capitalista, tanto em termos imediatos quanto mais gerais" (WILLIAMS, 2011, p.81)

Rodrigo e Macabéa estão aptos a qualquer trabalho, pois o processo de trabalho não os liga a nenhum especificamente. Diante do sistema vigente de produção, o escritor perde a aura e passa a datilografar, reproduzir e massificar a escrita. Através de Rodrigo S.M. podemos ver esse paradigma e, ironicamente, seu desnudamento dá ao livro $A$ bora da estrela força de contestação, uma vez que é capaz de estetizar e insurgir contra a questão da indústria cultural. Ideologicamente, Rodrigo S.M., embora finja não estar preocupado com as tendências, as coloca na narrativa como modo de reflexão. Nesse sentido, percebemos que o seu ofício, sua particularidade do trabalho subsome no trabalho que expressa o âmbito da indústria cultural, realizando-se aí no capitalismo mundial. O significado do seu trabalho parece ter sentido dentro de uma lógica que está no país, mas que não o pertence intrinsicamente, já que a realidade nacional é de uma modernização atrasada. Nesse aspecto, adota-se um 
sistema global, mas a dúvida do trabalho colocada por S.M. é justamente pelo fato de manterse na estruturação limitada nacional. Assim, o caráter fetichista de seu oficio de narrador é explicado:

\begin{abstract}
aquele que a adere à mercadoria cultural (...) no bem cultural a suposta ausência de valor de uso (que, na verdade, é valor de uso mediatizado) é hipostasiada no sentido de se transformar, ela própria, em valor de uso: a presumida inutilidade como emblema, que, em vez de subverter o caráter mercantil do produto, acaba por reforçar o caráter de valor de troca que ele, em uma sociedade capitalista, necessariamente possui. (DUARTE, 2007, p.32-33)
\end{abstract}

As reflexões da narrativa, sobretudo a respeito do valor de troca da estética, se colocam mostrando o caráter fetichista, entretanto isso é ironizado e assume aspecto de reflexão crítica no texto, embora ele não fuja disso. Rodrigo reflete sobre seu ofício, sobre seu país, sobre si mesmo, revelando que a busca de identificação é perpétua e assume valor de mercado, o que demonstra uma tendência ideológica e a impossibilidade de assumir uma autenticidade. Assim, refletindo Rodrigo vive como seus personagens cuja ideologia propagada é a do cinema, dos meios de comunicação. Clarice Lispector consegue representar, com $A$ bora da estrela, "o embate entre o escritor moderno, ou melhor, do escritor brasileiro moderno, e a condição indigente da população brasileira” (FUKELMAN, 1995, p.6). Portanto, existe algo além do insólito prefácio, da frouxidão do enredo e das alternâncias de linguagem: tratase da reflexão social importante que aparece na narração sob a égide da mercantilização da cultura. A busca pela expressão, a sondagem da criação estética revela, além de aspectos biográficos e de alteridade, as imbricações culturais em um país periférico. Assim, os aspectos sociais vão se definindo e estão longe de ser superficiais ou de segunda importância. São eles, a propósito, que conduzem à transformação da linguagem na obra.

Por fim, interessante é reiterar como que o livro, embora revele na narrativa a reprodução da estética massificada, consegue não endossar totalmente o fetichismo, colocando-o sob o signo da reflexão. As contradições na narração de Rodrigo e sua relação com Macabéa fazem com que as potencialidades críticas sejam despertadas a ponto de notarmos não uma plena subordinação estrutural ao trabalho do capital e da cultura de massa. Há mediações irônicas e contraditórias, como mostramos em Rodrigo S.M., que desnudam a autorreprodução da mercantilização cultural e as contradições na periferia como o Brasil. Ainda que reflita um ponto de vista independente das necessidades reais da população brasileira, como a influência da moda, é justamente esse girar em falso que mostra como o capital aqui se instala e a modernização ocorre de maneira parcial. Nesse aspecto, representa-se as determinações 
capitalistas e o seu controle social, que embora pretensamente universal, revela-se complexidades as quais fazem daqui Brasil.

\title{
THE COMMODIFICATION OF CULTURE IN THE NARRATION BY RODRIGO S.M., IN CLARICE LISPECTOR'S THE HOUR OF THE STAR
}

\begin{abstract}
This paper intends to understand how the narrative configuration performed by the narratorcharacter Rodrigo S.M. formalizes the active paradigm of the cultural industry in the aesthetic composition and the problematic of the national identity when following the new tendencies on the use of the language. The premise of the research relates to the difficulties posed at the moment of the narration, which, in addition to the discussion of self-writing and alterity, raise the "overwhelming feeling of the false position of everything that concerns Brazilian culture." (ARANTES, 1997, p.14). The novel A hora da estrela, due to the narrative built, is important in the questioning of the limits of artistic representation and in the ambiguous status of the Brazilian condition, revealing that "life in late capitalism is a continuous rite of initiation. Everyone has to show that they fully identify with the power of those who do not cease to receive blows ". (ADORNO, 2006, p. 127) According to the characters, Rodrigo and Macabéa, the novel by Clarice Lispector brings the work of the writer closer to that of typewriter, contributing to show the ideological emptying of industrial society and the insertion of culture into the logic of fetishism and commodification. Thus, this analysis will reflect on how the narrator, despite his rationalization, is atrophied in the capacity to narrate, reproducing the implacable ideology of the masses.
\end{abstract}

KEYWORDS: The Hour of the Star, Cultural industry; Narrator.

\section{REFERÊNCIAS}

ADORNO, Theodor W. \& HORKHEIMER, Max. Dialética do esclarecimento: fragmentos filosóficos. Trad. Guido Antonio de Almeida. Rio de Janeiro: Ed. Zahar, 2006.

ARANTES, Paulo Eduardo. \& ARANTES, Otília Beatriz Fiori. Sentido da formação: três estudos sobre Antonio Candido, Gilda de Mello e Souza e Lúcio Costa. Rio de Janeiro: Paz e Terra, 1997.

ARANTES, Paulo Eduardo. Sentimento da dialética na experiência intelectual brasileira. Rio de Janeiro: Paz e Terra, 1992.

BENJAMIN, Walter. O autor como produtor. In: Magia e técnica, arte e política. Trad. Sérgio Paulo Rouanet. 7ed. São Paulo: ed. Brasiliense, 1994.

CANDIDO, Antonio. Literatura e Sociedade. 11ed. Rio de Janeiro: Ed. Ouro sobre azul, 2010. CHASIN, José A. “O poder do real”. In: O mundo hoje 95/96. São Paulo: Ensaio, 1995.

DUARTE, Rodrigo. Teoria crítica da indústria cultural. Belo Horizonte: Editora UFMG, 2007.

FUKELMAN, Clarice. "Escrever estrelas (ora,direis)" In: LISPECTOR, Clarice. A hora da estrela. 23ed. Rio de Janeiro: Francisco Alves, 1995.

GOTLIB, Nadia. Clarisse: uma vida que se conta. São Paulo: Ática, 1995.

LISPECTOR, Clarice. A hora da estrela. 23ed. Rio de Janeiro: Francisco Alves, 1995.

NUNES, Benedito. O drama da linguagem: uma leitura de Clarice Lispector.2ed. São Paulo: Ática, 1989.

O dorso do tigre. São Paulo: Perspectiva, 1969. 
SCHWARZ, Roberto. Nacional por subtração. In: Que horas são? ensaios. São Paulo: Cia das letras, 1987.

WILLIAMS, Raymond. Cultura e Materialismo. Trad. André Glaser. São Paulo: Ed. Unesp, 2011.

Recebido em: 03/01/2020.

Aprovado em: 20/01/2020. 